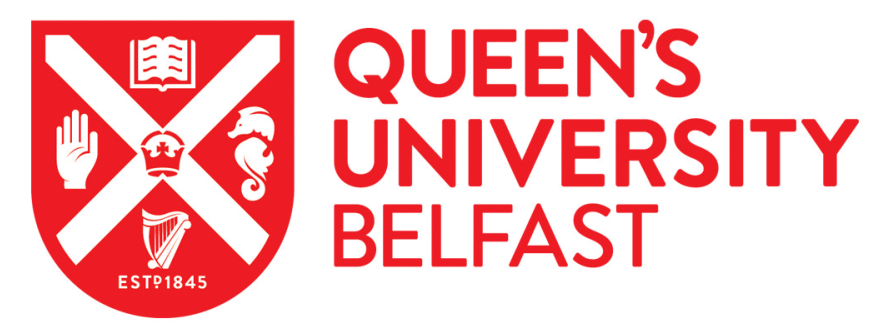

\title{
Bridge weigh-in-motion using fibre optic sensors
}

Lydon, M., Taylor, S., Doherty, C., Robinson, D., OBrien, E. J., \& Žnidarič, A. (2017). Bridge weigh-in-motion using fibre optic sensors. Proceedings of ICE - Bridge Engineering, [BRIDGE-D-15-00033].

https://doi.org/10.1680/jbren.15.00033

Published in:

Proceedings of ICE - Bridge Engineering

Document Version:

Publisher's PDF, also known as Version of record

Queen's University Belfast - Research Portal:

Link to publication record in Queen's University Belfast Research Portal

Publisher rights

Copyright @ ICE Publishing, all rights reserved.

Permission is granted by ICE Publishing to print one copy for personal use. Any other use of these PDF files is subject to reprint fees

\section{General rights}

Copyright for the publications made accessible via the Queen's University Belfast Research Portal is retained by the author(s) and / or other copyright owners and it is a condition of accessing these publications that users recognise and abide by the legal requirements associated with these rights.

Take down policy

The Research Portal is Queen's institutional repository that provides access to Queen's research output. Every effort has been made to ensure that content in the Research Portal does not infringe any person's rights, or applicable UK laws. If you discover content in the Research Portal that you believe breaches copyright or violates any law, please contact openaccess@qub.ac.uk. 


\section{Bridge weigh-in-motion using fibre optic sensors}

1 Myra Lydon PhD, BEng, MICE postdoctoral research fellow, Intelligent Infrastructure Group, CERC, School of Planning, Architecture, and Civil Engineering, Queen's University Belfast, Belfast, Northern Ireland (corresponding author: mlydon01@qub.ac.uk)

2 Su E. Taylor PhD, MISHMII, MIIFC

Professor, Director of CERC, School of Planning, Architecture, and Civil Engineering, Queen's University Belfast, Belfast, Northern Ireland; Dean of Research for Faculty of Engineering and Physical Sciences, Queen's University Belfast, Belfast, Northern Ireland

3 Ciaran Doherty CEng, MIEI

Structural Engineer, Amey Consulting Belfast, Belfast, Northern Ireland
4 Des Robinson PhD

Senior Lecturer, Intelligent Infrastructure Group, CERC, School of Planning, Architecture, and Civil Engineering, Queen's University Belfast, Belfast, Northern Ireland

5 Eugene J. O'Brien BE, MEngSc, PhD, CEng, FIEl, MIStructE Professor, School of Civil, Structural \& Environmental Engineering, University College Dublin, Dublin, Ireland

6 Aleš Žnidarič CEng, MSC

Head of Section for Bridges and Engineering Structures, Slovenian National Building and Civil Engineering Institute, Ljubljana, Slovenia
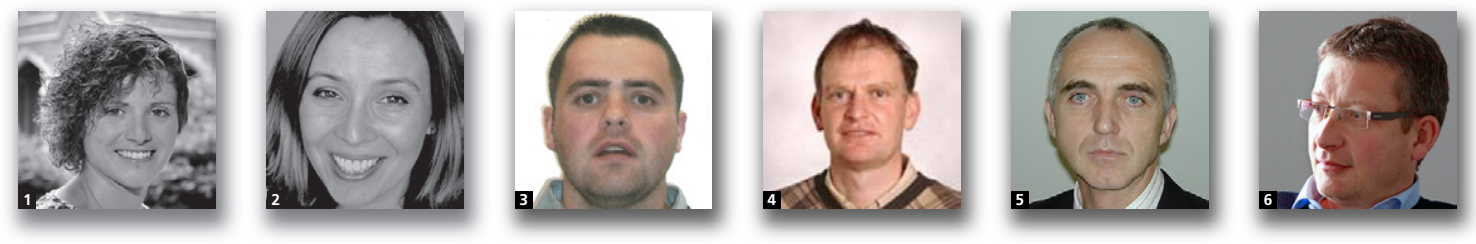

Bridge weigh-in-motion systems were introduced in the 1970 s as a structural health monitoring tool for road bridges. They help bridge operators determine the cause of induced strain in bridges and collect statistics on vehicle weight, class and frequency. There have been over 3000 installations in 25 countries worldwide, which has led to vast improvements in data post-processing. However, existing systems are based on electrical resistance strain gauges, which can be prohibitive in achieving data for long-term monitoring of rural bridges due to power consumption. This paper introduces a new low-power system using fibre optic sensors, which has been pioneered in Northern Ireland. A series of fibre optic sensors were attached to the soffit of an existing integral bridge with a single span of $19 \mathrm{~m}$. The site selection criteria and full installation process are described in this paper. A method of calibration was adopted using live traffic at the bridge site, based on which the accuracy of the system was determined. New methods of axle detection for bridge weigh-in-motion were investigated and verified in the field.

\section{Introduction}

The UK government has committed to treble annual investment in major road schemes by 2020-2021, investing over $£ 10$ billion to affect the repair and renewal of the national and local road networks. In the UK, bridge structures represent $2 \%$ of the national network length but $30 \%$ of its total asset value. The 2013 report card on US infrastructure stated that an annual investment of US\$ 20.5 billion is required to eliminate the backlog of all cost-beneficial US bridge needs by 2028 (IRC, 2016). Long-term financial planning is required to maximise the potential of this investment by strategic management of ageing infrastructure.

Structural health monitoring systems can provide valuable information on bridge capacity but currently do not provide statistical data on the frequency and loading of live traffic. Bridge weigh-in-motion (BWIM) systems provide a tool for determining the cause of induced strain in bridges and for the collection of statistics on vehicle weight, class and frequency. BWIM was first introduced by Moses (1979) and subsequently developed by Peters (1986) to a system for weighing trucks using culverts known as Culway. The next major advance was a prototype system developed under the Wave project in the 1990s (O'Brien et al., 1999). The concept is to use an existing bridge as a weighing scale to establish gross vehicle weight (GVW) and axle loads, without interruption to traffic flow. The data collected generates statistical information on bridge loading, which can be used as an ongoing management tool to strategically evaluate and manage safety of infrastructure assets. As well as gathering statistics on traffic, BWIM systems have the potential to provide a cost effective and, if needed, portable method of gathering information that can be used to determine the whole-life performance of bridge structures. Structural health monitoring and BWIM can provide more accurate information on the loading conditions specific to an individual structure while at the same time providing direct 
information on the condition of the structure (Žnidarič and Lavrič, 2010).

This paper focuses on the installation, calibration, data interpretation and analysis of a next-generation BWIM system in Northern Ireland. Existing BWIM systems are based on electrical resistance strain gauges - the installation described in this paper is unique as it is the first fibre optic BWIM system. Fibre optic sensors (FOSs) are passive and are unaffected by voltage drops that affect the output of electrical resistance strain gauges (Hayes and Simmonds, 2002). This system provides a low-power alternative to conventional BWIM sensors, which is particularly advantageous for rural bridge sites. Kalin et al. (2006) has suggested that FOSs could provide a good alternative to existing systems. The advantages of FOSs for long- and short-term bridge monitoring have been well documented in the literature (Casas and Cruz, 2003; Inaudi, 2010; Maaskant et al., 1997; Measures, 2001).

The equipment layout is also unique as it is one of very few sites in the world to combine a pavement weigh-in-motion system (PWIM) and full BWIM at one location. The first step in this research was to select a suitable bridge structure for the system to be installed and operated on. Based on the selection criteria detailed in Section 3, a bridge site was identified at Loughbrickland in Northern Ireland (Figure 1). Both the

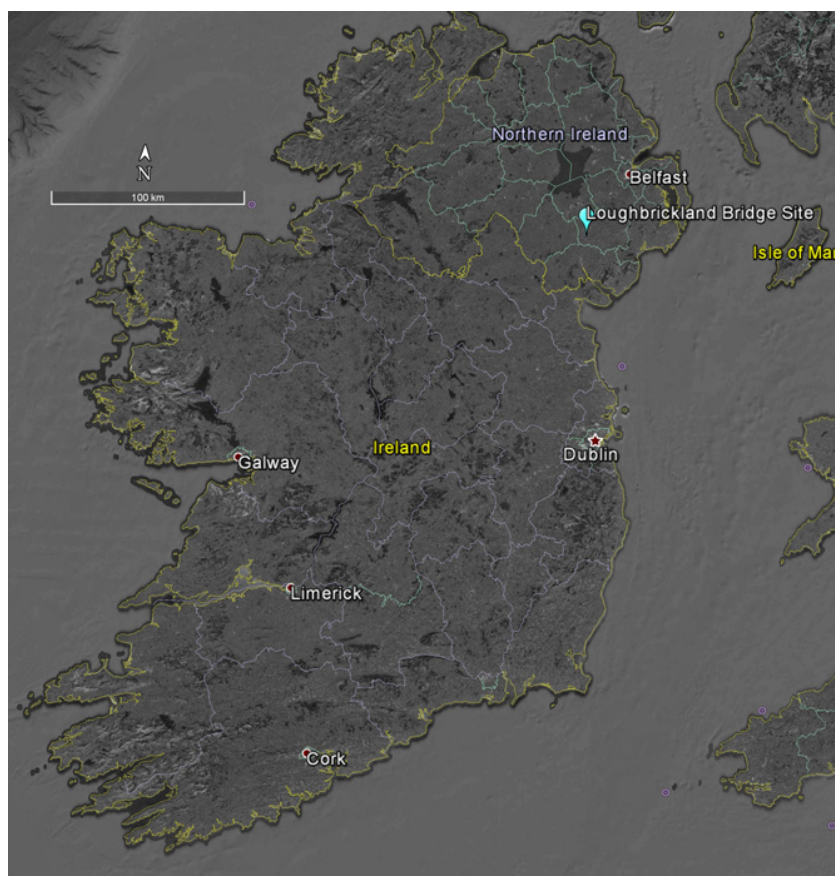

(a)
BWIM and PWIM systems were calibrated and the accuracy of each system was determined based on the readings obtained using statically weighed traffic data. The systems are now fully operational and continuous data acquisition is underway to provide information for future analysis of loading, resistance and dynamic amplification.

\section{Review of previous \\ weigh-in-motion systems}

The concept of PWIM was developed in the early 1950s in the USA by the Bureau of Public Roads (Norman and Hopkins, 1952). PWIM systems serve two major functions - the data collected can be used for future planning and management of road networks but their main purpose is to identify and subsequently reduce illegally overloaded vehicles. If uncontrolled, overloaded vehicles may cause premature deterioration of infrastructure. There are a number of PWIM technologies; for example, the bending plate system consists of an instrumented plate whose flexure is proportional to the wheel weight. All other technologies have pressure-sensitive sensors embedded in the road surface in a strip perpendicular to the direction of traffic. Piezo-polymer, piezo-ceramic and piezo-quartz sensors are inexpensive and easy to install, which has made them the most common PWIM systems in the UK. Inaccuracies in these systems are often caused by sensitivity to temperature, poor sensor technology or bouncing of the vehicle on an uneven

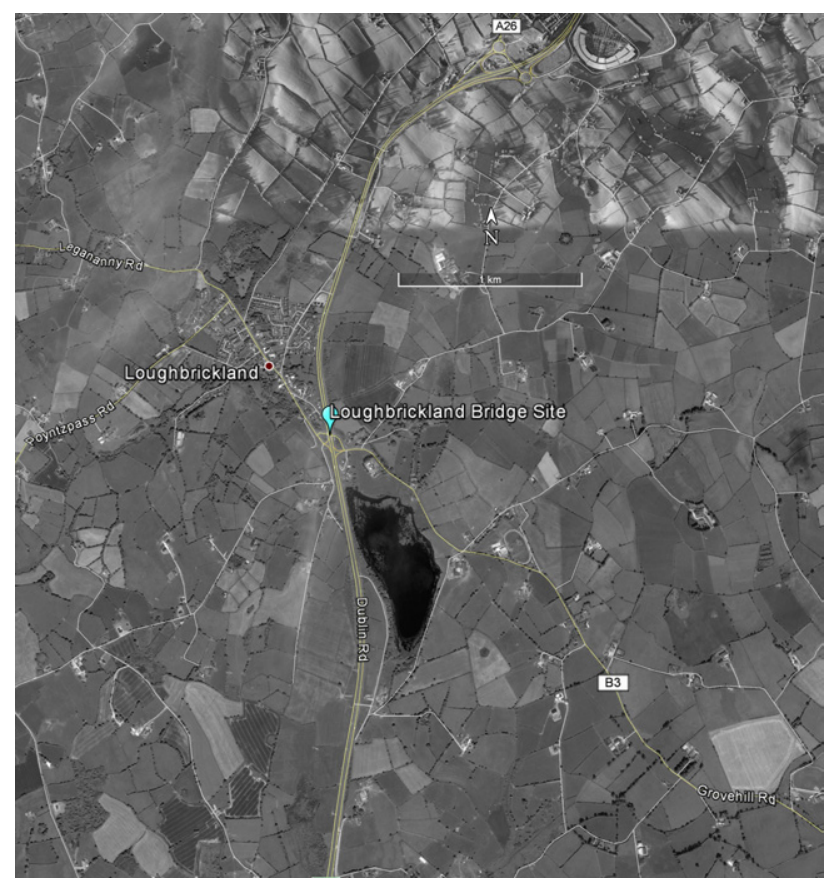

(b)

Figure 1. Geographic location of bridge site: (a) Ireland; (b) detail of Loughbrickland area. Imagery @2017 DigitalGlobe, Google, Landsat / Copernicus, Map data @2017 Google 
road surface. Additionally, PWIM systems can provide biased data as road users are aware of their presence and it is possible for drivers of overloaded vehicles to choose an alternative route.

A BWIM system uses the measurement of a varying property of a bridge, usually strain, to estimate the weights of passing axles. The main advantage of BWIM over PWIM is its nondestructive implementation and its ability to provide completely unbiased traffic weight data. In BWIM, an existing bridge is instrumented with a series of strain sensors installed on the bridge soffit. As it takes a vehicle up to a second to cross the bridge, the inaccuracies caused by axle bounce are small and gross weights in particular tend to be quite accurate. The system consists of two elements - one to measure strain and infer weights, and one to detect axles (Moses, 1979). Axle detectors were originally placed on the road surface but axle detection today is generally performed by sensors under the bridge (Kalin et al., 2006; O'Brien et al., 2012; Žnidarič et al., 2010). In the original algorithm proposed by Moses (1979), axle weights are found by minimising the sum of squares of differences between measured and theoretical responses to the passing truck. The theoretical response is the product of axle weight and the relevant influence ordinate, summed over all axles on the bridge. In recent years there have been extensive developments in the area of BWIM, as documented in the literature (Lydon et al., 2015; Richardson et al., 2014). In the most sophisticated algorithms, the static equations of Moses (1979) have been replaced by a system of differential equations of motion in an approach known as moving force identification (González et al., 2008; Law and Fang, 2001; Law et al., 1999; OBrien et al., 2009; Rowley et al., 2009). The most recent moving force identification research is reported by $\mathrm{Zhu}$ et al. (2013) and Corbaly et al. (2014).

\section{Site selection criteria}

Site selection criteria were developed to choose the most appropriate testing location. The selection criteria were closely based on the recommendations of the Cost 323 committee (Cost 323, 1999). This specification is targeted at both PWIM and BWIM installations and some of the recommendations apply to both systems. However, some specific bridge criteria are also given, as summarised in Table 1.

Significant criteria when selecting the bridge site were traffic flow and span, together with the road surface roughness, carriageway type, access and the existence of a convenient power supply. A bridge of no more than 5 years old was considered suitable as information on its construction was readily available, thus saving time on a full non-destructive evaluation. It was also considered that pavement damage was less likely in a new build and this was proven by the latest road surface profilometer readings, thus improving the accuracy of the system as pavement unevenness has been found to be a key obstacle to achieving accurate BWIM results (Lavric et al., 2008). The hierarchy of the remaining selection criteria was geographical location, bridge skew, road geometry and proximity to a static weigh station.

A catalogue of recently completed road improvement schemes in Northern Ireland was obtained from the Department of Regional Development of Northern Ireland. From this list, the dual carriageway road schemes completed between 2009 and 2012 were identified. Overpass structures were discounted as they provide weight data for minor roads with a considerably lower volume of traffic. Location was considered as the next criterion and the proximity of a static weigh station. There are 13 weighbridges in Northern Ireland. A cross-comparison of these locations with the locations of newly constructed bridges indicated that the site at Loughbrickland in Co. Down was the most suitable location for the installation. It is an underpass to a busy dual carriageway, there are 10000 to 12000 vehicles travelling on the carriageway in each direction daily and it is located within $3 \mathrm{~km}$ of a static weighbridge. The bridge structure forms part of the main Dublin to Belfast A1 route, which is an important link between the ports of Dublin, Warrenpoint and Belfast, and forms a strategic cross-border economic link to the Republic of Ireland.

The integral bridge at Loughbrickland was constructed in 2010 and has a single span of $19 \mathrm{~m}$. The superstructure

Table 1. Bridge selection criteria (Cost 323, 1999)

\begin{tabular}{llc} 
Criterion & Optimal & Acceptable \\
\hline Bridge type & $\begin{array}{c}\text { Steel girders, prestressed concrete girders, reinforced concrete } \\
\text { girders, culvert, steel orthotropic decks }\end{array}$ & Concrete slab \\
$\begin{array}{l}\text { Span length } \\
\text { Traffic density }\end{array}$ & $5-15 \mathrm{~m}$ - Free traffic - no congestion (traffic jam) \\
$\begin{array}{l}\text { Evenness of the pavement } \\
\text { before and on the } \\
\text { bridge }\end{array}$ & $\begin{array}{l}\text { Class I or class II } \\
\text { (according to Table 1 of Cost } 323 \text { report) }\end{array}$ & $8-35 \mathrm{~m}$ \\
& $<10^{\circ}$ & Class III \\
\end{tabular}


consists of 27 prestressed concrete $\mathrm{Y} 4$ beams each $1 \mathrm{~m}$ in depth, spaced at $1.22 \mathrm{~m}$ centres. A $200 \mathrm{~mm}$ cast in situ concrete deck is overlaid and supported by permanent non-structural glass fibre reinforced concrete formwork, which spans transversely between the main beams. The Cost 323 committee (Cost 323, 1999) recommends a skew of less than $10^{\circ}$ but a survey of the bridge stock found that the majority of relatively new bridge structures in the region have a skew above $10^{\circ}$. The skew on the Loughbrickland underpass is $22.7^{\circ}$. However, it was considered that the large skew would also address the challenges of applying a BWIM system on a skewed bridge and to extend the application of BWIM systems. Other issues that were considered included the availability of a power supply and a location for a roadside cabinet. Overall, the bridge site at Loughbrickland met the requirements of the site selection criteria and was selected as a suitable structure for implementation of the next-generation BWIM system.

\section{Site layout and installation}

The bridge carries four traffic lanes, two in each direction, as well as two peripheral lanes for traffic joining/exiting the carriageway (Figure 2). A large central reservation separates the

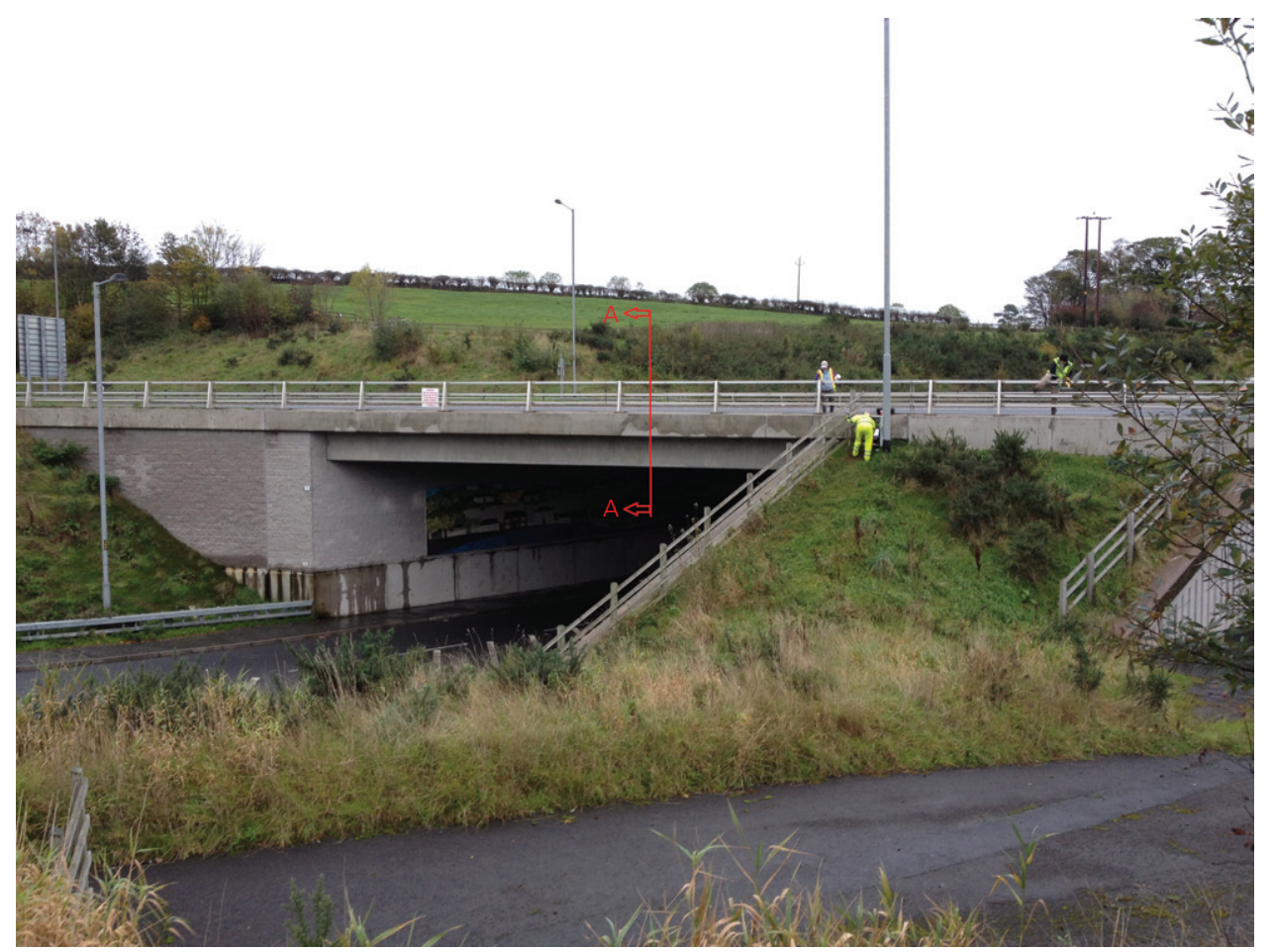

(a)

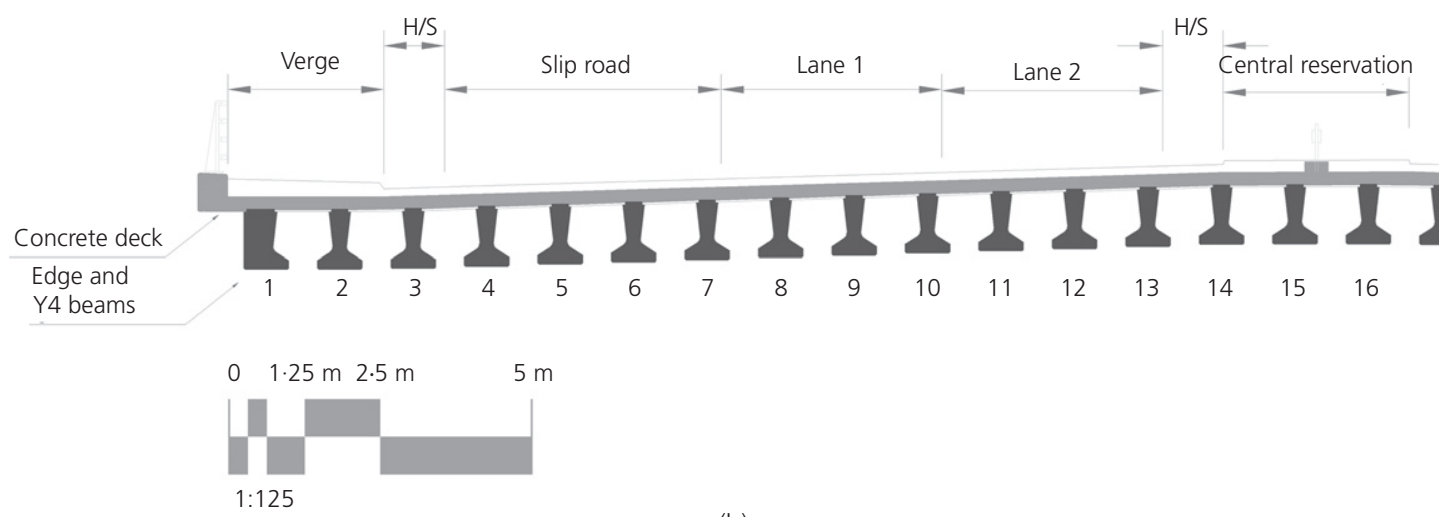

(b)

Figure 2. (a) Site elevation; (b) cross-section ( $\mathrm{H} / \mathrm{S}=$ hard shoulder) 
northbound and southbound carriageways. The northbound section was chosen for instrumentation as the layout allowed for a suitable location for the equipment.

A full BWIM system was installed on the bridge structure and a piezo-polymer PWIM system was embedded in the pavement on the approach to the structure. The purpose of the PWIM system was to provide a method of comparing the results from the next-generation BWIM system with those obtained from an existing method of WIM.

\subsection{PWIM system}

The PWIM system is a conventional piezo-loop-piezo arrangement and a visual image of the vehicle is captured using CCTV equipment. The piezo-polymer sensors are used to weigh the axles and the loop is used to assist in the classification of vehicles. As the installation required the closure of lanes on a national road, it was carried out during the night and one lane remained open at all times during the installation (Figure 3).

\subsection{BWIM system}

A fibre optic BWIM sensing system was implemented and installed in various stages. The optimum location of the sensors was determined from a three-dimensional numerical model of the structure. Details of the development of the sensors and fixing methods for the system are described by Lydon et al. (2014). The system was progressively developed

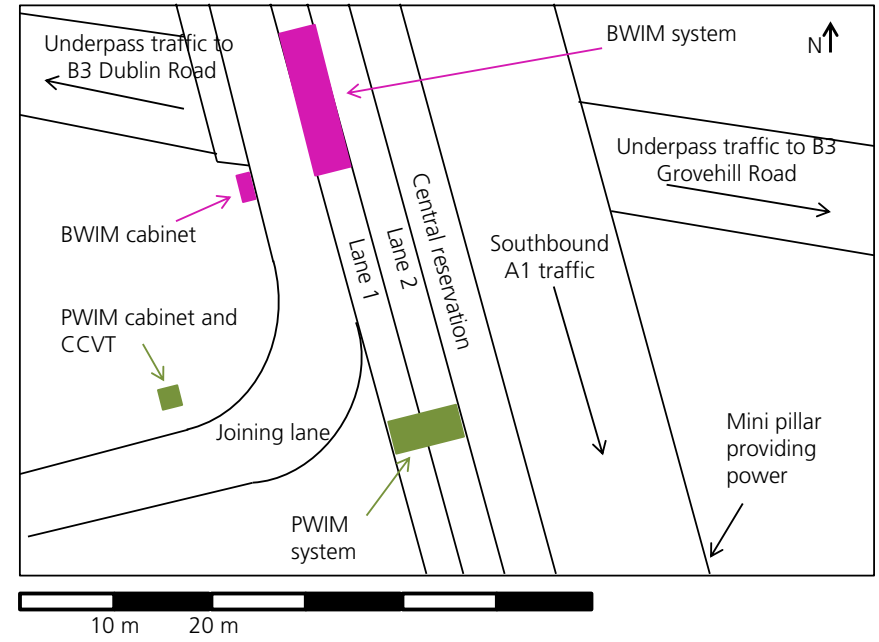

(a)

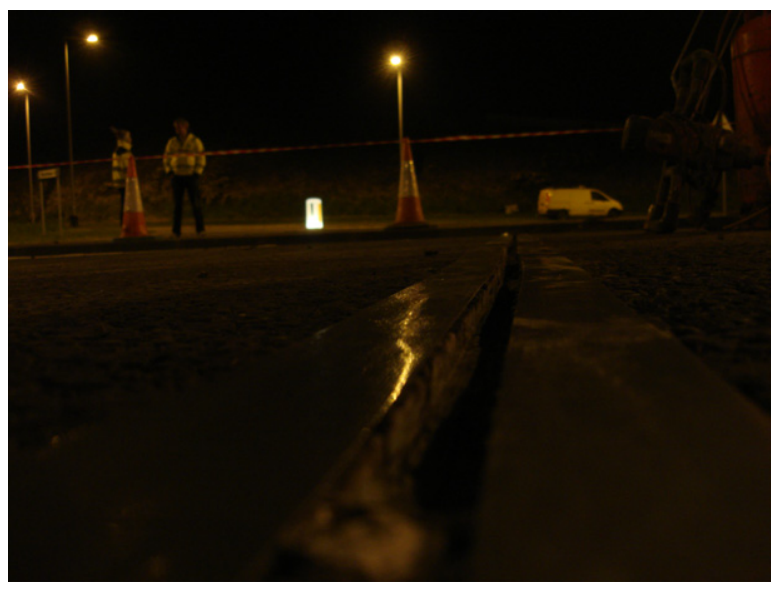

(b)

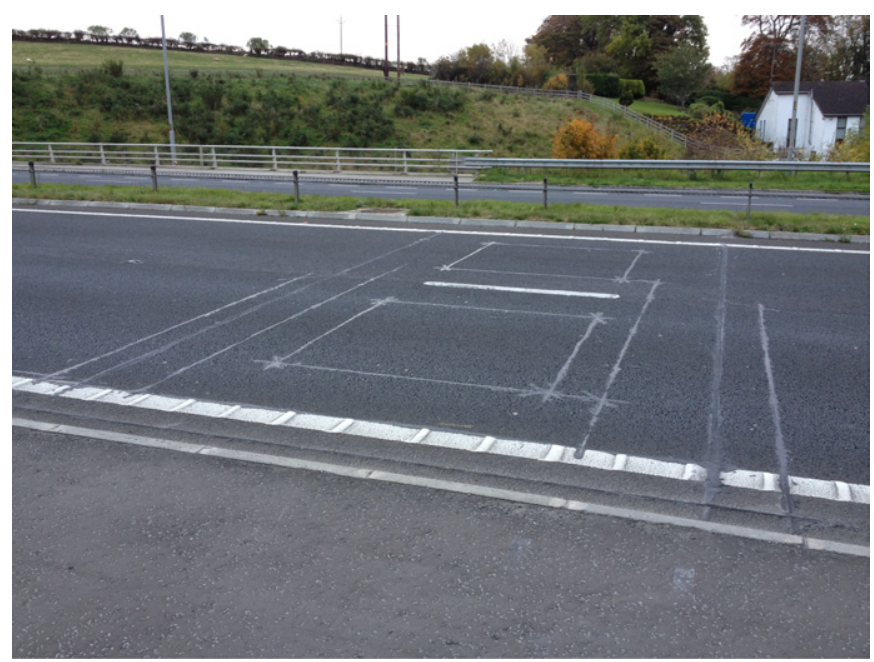

(c)

Figure 3. (a) Site schematic of Loughbrickland; (b) PWIM installation; (c) completed PWIM installation 
based on the results from the numerical modelling and a staged installation process. The light source and interrogation elements for the system were in a combined unit that allows for dynamic measurement of hundreds of sensors at scanning rates up to $1 \mathrm{kHz}$. The unit outputs sensor wavelength data to an external computer via an ethernet port and all output settings can be customised via the sensing analysis software. A security cabinet was custom made to safely house the equipment. It was installed on the supporting wall on the south west side of the bridge and electricity was brought to the cabinet from the PWIM cabinet. Figure 3(a) shows a schematic illustration of the site and the equipment locations.

The BWIM sensors had two different functions - weighing sensors and axle detecting sensors. Each weighing sensor consisted of a non-metallic $10 \mathrm{~mm}$ gauge-length fibre Bragg grating (FBG) sensor mounted on a $5 \mathrm{~mm}$ stainless steel dogbone plate, which had the effect of amplifying the bridge beam strain (Lydon et al., 2014). The plate was attached to the soffit of the longitudinal beams and orientated to measure strain in the longitudinal direction. Nothing on the road (NOR) axle detecting sensors refer to sensors located in the positions defined in previous research (Kalin et al., 2006) and the actual FBG sensor type is consistent with those employed for weighing. As illustrated in Figure 4, six beams were instrumented to allow for the measurement of change in strain in the longitudinal direction, and eight sensors were installed for NOR axle detection. Additional axle detecting sensors were installed to test a new strategy for axle detection. This involved the installation of four additional $10 \mathrm{~mm}$ gauge length FBG sensors, which were located near the support. The configuration of sensors installed during this phase is detailed in Section 7.1 they were orientated to measure change in strain both vertically (i.e. bearing strain under a wheel load) and at $45^{\circ}$ to the vertical.

As previously mentioned, a dog-bone plate was employed as a strain amplification method to enhance the sensitivity of the system (Lydon et al., 2014). To assess the possibility of further amplification, three weighing sensors were aligned at the midspan location of beam 7, as shown in Figure 4. The output signal for the three sensors was summed at the post-processing stage, thus allowing more accurate measurements. This was done to address recent findings that indicate the traditional approach of adding the contribution of all weighing sensors located across the width of the deck can reduce the potential accuracy of the system. This takes into account the fact that the calculated influence line would vary with the transverse position of the truck (Corbaly et al., 2014).

\section{System calibration}

The initial calibration day was used for calibration of the PWIM system, which was installed prior to the BWIM system.
However, as three of the BWIM NOR axle detecting sensors on the south side of the structure had also been installed at this stage, results were recorded to assess the sensitivity of these sensors. Calibration was carried out on 7 June 2013 using a pre-weighed calibration truck and conformed to the 'full repeatability' condition of Cost 323 (Jacob, 2000; Jacob et al., 2000). The close proximity of a static weigh station proved valuable during this process as it allowed for accurate weighing of the calibration vehicle.

Even though this was the recommended method of calibration, the BWIM system was installed in various stages and after each stage it was necessary to have a method of determining the accuracy of the system. As further calibration days of this nature were excessively expensive, an alternative method of calibration was required. A cost-effective alternative was to calibrate the BWIM system by comparing the results with those obtained from the calibrated PWIM system. This method of assessing the accuracy of one system using an inaccurate measurement is long established in the medical literature (Altman and Bland, 1983). This allowed for the accuracy of the BWIM system to be checked on any given day without the need for pre-arranged calibration trucks. Both systems were time-synchronised to allow for easy comparison of the results. An additional independent accuracy check was developed in conjunction with the Driver Vehicle Agency of Northern Ireland (DVA), whereby the results from both the PWIM and BWIMs system could be compared with those obtained from the static weighbridge. The comparison of the two weigh-inmotion technologies was used as an error 'indicator' for dayto-day monitoring while the DVA measurements provided 'ground truth' data for assessing the accuracy of both systems.

Regular enforcement checks are carried out periodically by the DVA at the various weighbridges across Northern Ireland. This is to ensure that vehicles comply with legal weight limits as well as compliance with a wide range of other vehicle legislation. The enforcement officers randomly select vehicles from the live traffic to be diverted to the weigh station. The vehicle is then assessed to determine if it meets all of the compliance requirements. Liaising with the DVA led to a series of test days at Loughbrickland.

\section{PWIM results}

The purpose of installing the PWIM system on the approach to the bridge was to provide a means of testing the BWIM system. The results from both systems were compared to assess the accuracy of the axle detection in the BWIM system. However, due to the PWIM inaccuracy issues detailed in this section, the BWIM axle weight and GVW calculations presented in this paper are only those that were verified by the DVA at the static weigh station. 


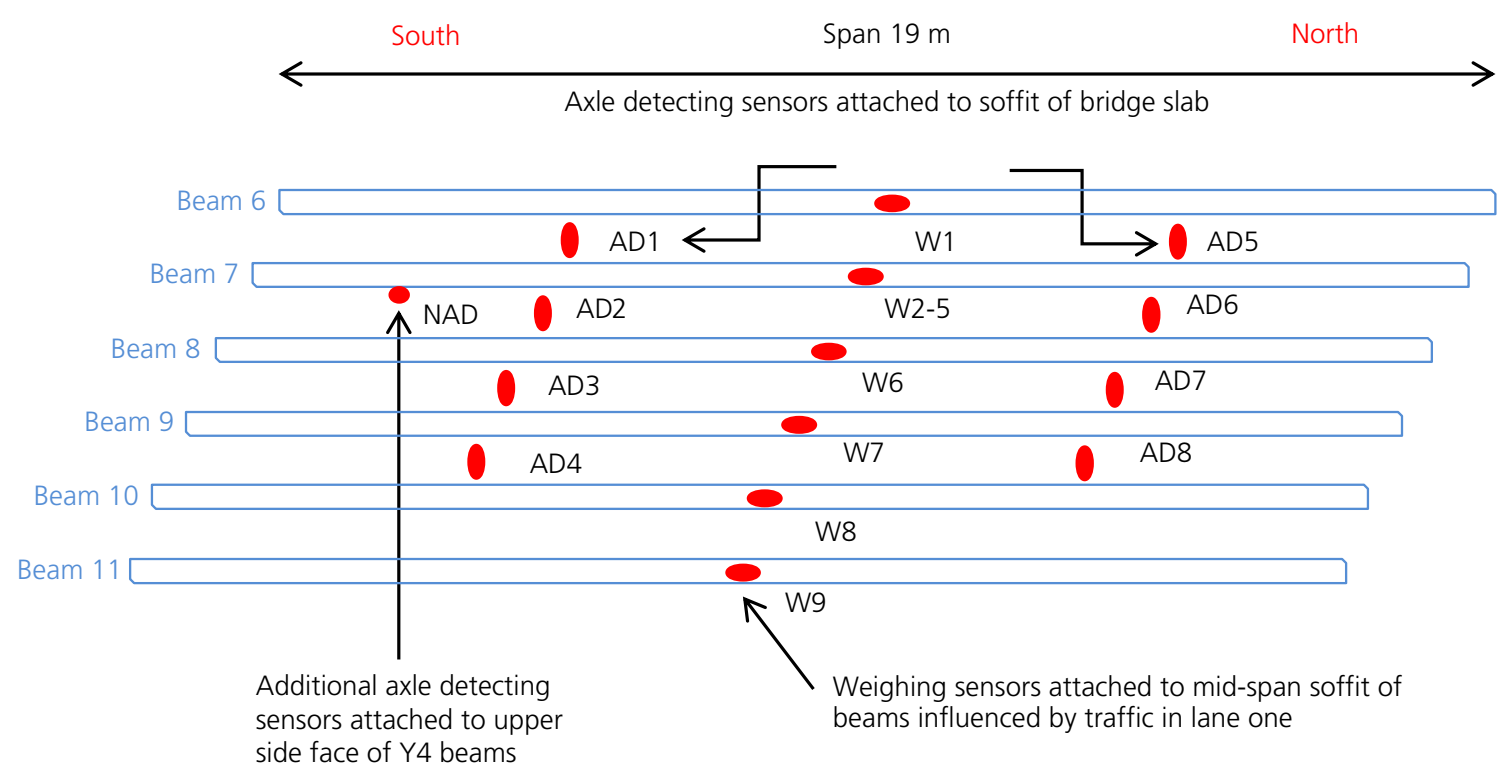

(a)

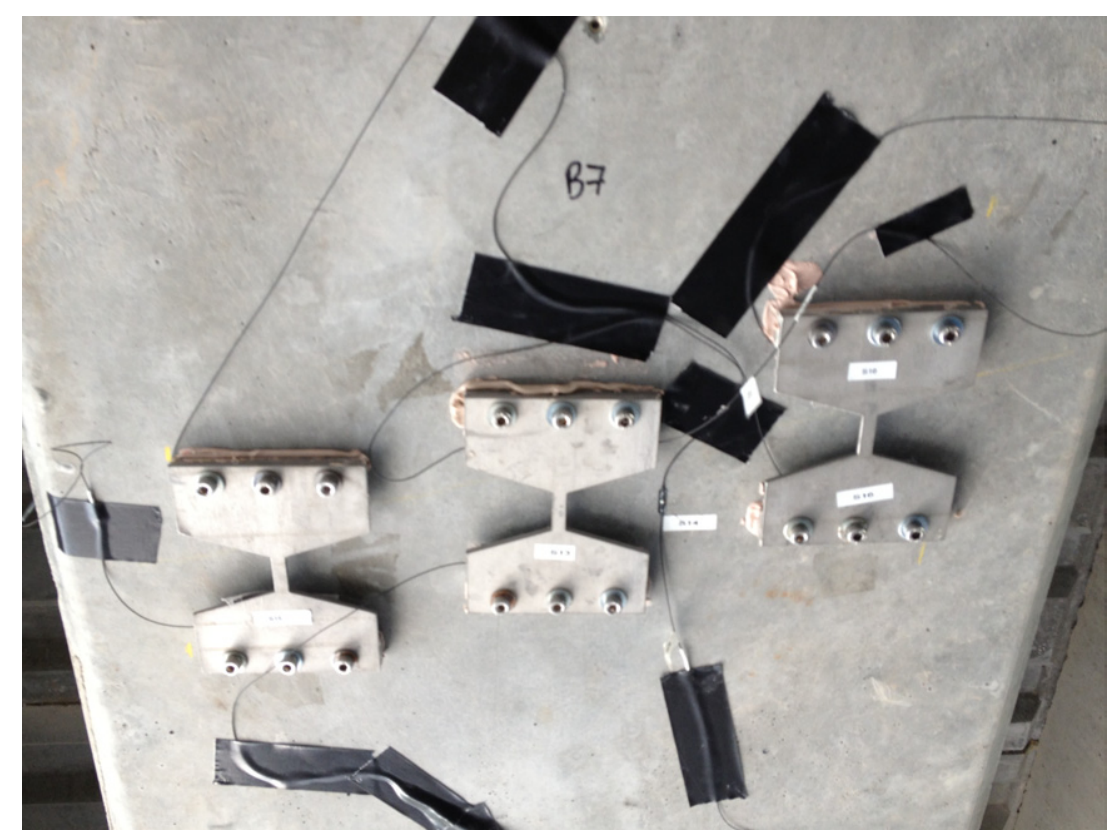

(b)

Figure 4. BWIM sensors: (a) full sensor layout; (b) weighing sensor configuration on beam 7 (W2-W5)

After the initial calibration, the PWIM system was found to operate to a $\mathrm{B}(10)$ accuracy class; that is, $95 \%$ of gross weights were accurate to $\pm 10 \%$ (Cost 323,1999$)$. In the subsequent months, a large volume of traffic data was collected at the site and statistical analysis of the data provided interesting information on the characteristics of the traffic at the site (Doherty et al., 2014). At various stages during the installation of
BWIM equipment, the PWIM system provided a reference to give an indication of how the BWIM system was operating. However, to objectively determine the accuracy class, a comparison was made with static weights and the DVA test days provided this information. The first DVA testing day indicated that the PWIM system was under-weighing vehicles by about $25 \%$. Piezo-polymer sensors are highly sensitive to temperature 
and a temperature non-linearity (TNL) curve is generally used to correct the resulting errors. In this case, it was found that the inaccuracy was due to a problem with the implementation of the TNL curve. This finding significantly reduced confidence in the PWIM system and raised doubt over all the data that had been collected. The system supplier employed a method of back calibrating the existing data using the average front axle weight of a class 1 (car) vehicle. Using the above combination of weight data enabled a recalibration of the system, but the long-term success of this is yet to be determined. A similar method has been previously employed for the Australian weigh-in-motion system Culway (Koniditsiotis, 2000).

There is no doubt the PWIM system was a valuable asset to the project and the video footage proved useful when investigating anomalies in the site results. The camera has a clear view of the carriageway and records continuously. The PWIM system also provided accurate information on the axle configuration of all vehicles crossing the site. This information was instrumental in confirming the success of the new strategy of axle detection.

\section{BWIM results}

The BWIM system installed at Loughbrickland can be used for continuous monitoring of the structure and the live traffic. The scanning frequency for the interrogation system was set to $500 \mathrm{~Hz}$. A sensitivity analysis using the site data found this scanning rate resulted in the most efficient file size while still providing a sufficient number of data points for clear axle detection. The strain signals collected on site were analysed in two ways. Firstly, a data management software package was used to visualise the signals. This was done to determine if the sensors were sensitive enough to provide the distinct peaks required for axle detection. Secondly, selections of strain history files for pre-weighed vehicles crossing the structure were selected, and these files were processed using an existing BWIM software package, The accuracy of the signals for individual axle and GVW calculations was then determined.

One of the goals of this research was to develop an effective method of axle detection with nothing on the road. NOR axle detection has been used on a significant number of commercial BWIM installations. It involves two sets of strain sensors that are fixed to the soffit of the bridge deck at a known distance apart. The truck event is seen as a series of peaks in the strain signal corresponding to the passage of the axles. The NOR algorithm determines the vehicle velocity by correlating the two time-shifted strain signals. Knowing the velocity allows the axle spacing to be found. The main challenge for NOR axle detection is to increase the number of successful axle identifications, particularly when using less suitable structures.

Phase one of the installation of BWIM sensors at Loughbrickland included three NOR axle detecting sensors (AD1, AD2 and AD3), orientated to measure transverse strain on the soffit of the in situ bridge slab. These three sensors form part of the set of axle detecting sensors in the south half of the structure, as shown in Figure 4. The results presented were obtained from the BWIM system on 7 June 2013 when an official Cost 323 calibration was carried out on the PWIM system. The weights of the vehicles causing the strain events were obtained from the PWIM system and can be taken to be correct to accuracy class $\mathrm{B}(10)$. These data was chosen to allow for the comparison of a wide range of vehicle types rather than the single vehicle used for the calibration.

A selection of data was identified for the calibration day and the systems were time-synchronised to allow for easy comparison of data. The vertical axis on each of the following graphs represents the measured change in strain induced at a sensor location due to a passing vehicle on the road overhead. A moving average smoothing method was applied to each strain signal presented, as it is common practice to filter the signals. This method was found to be sufficient to remove any false peaks from the signals and allow for clear axle detection. The vehicle types according to the UK Highways Agency class references shown in Table 2 are also identified in the graphs.

Initially the results were assessed to determine if the system was sufficiently sensitive to capture a class 2 (light goods) vehicle as sensitivity to lighter axles has been raised as an issue for NOR systems. The DVA also identified this vehicle class as having the highest violation rate in terms of overload. In 2013, the UK Vehicle and Operator Services Agency (VOSA) now known as the Driver and Vehicle Standards Agency (DVSA) published figures stating that $89 \%$ of vans stopped by the

Table 2. UK Highways Agency vehicle classes

\begin{tabular}{lllll} 
Class $\mathbf{1}$ & Class $\mathbf{2}$ & Class $\mathbf{5 2}$ & Class $\mathbf{5 5}$ & Class $\mathbf{5 6}$ \\
$\begin{array}{c}\text { Car, light van, } \\
\text { taxi }\end{array}$ & $\begin{array}{c}\text { Light goods } \\
\text { vehicle }\end{array}$ & $\begin{array}{c}\text { Articulated, 2-axle tractor + 2-axle } \\
\text { semi-trailer }\end{array}$ & $\begin{array}{c}\text { Articulated, 2-axle tractor + 3-axle } \\
\text { semi-trailer }\end{array}$ & $\begin{array}{c}\text { Articulated, 3-axle tractor + 3-axle } \\
\text { semi-trailer }\end{array}$ \\
\hline
\end{tabular}




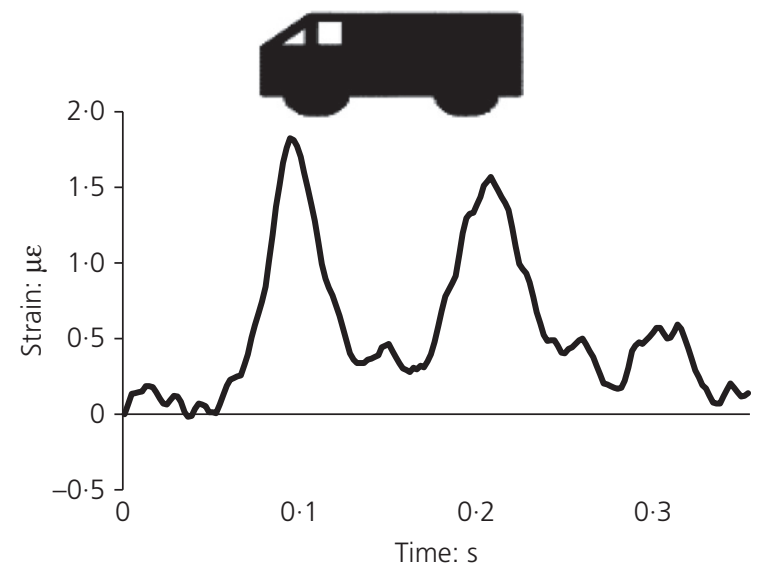

Figure 5. Clear peak detection for class 2 vehicle

agency in 2012 were overloaded (DVSA, 2013). Figure 5 shows clear peaks corresponding to each axle for this class of vehicle. According to the PWIM system, this particular vehicle had weights of $1.78 \mathrm{t}$ and $2.07 \mathrm{t}$ in the first and second axles respectively.

A common issue relating to NOR axle detectors is missed peaks, particularly in groups of axles. The Figure 6 illustrate that the FOS system achieved clear peak detection in a variety of situations. Figure 6 shows the results due to the passing of a partially loaded $(21 \mathrm{t}$ ) class 56 vehicle and an overloaded (49 t) class 55 vehicle. All three peaks corresponding to the axles of the tridem are clearly visible in both cases. The axles of the tandem in the class 56 vehicle are also clearly distinguishable.

These results demonstrated that the next-generation BWIM system installed on site can provide accurate axle detection data. However, this method of axle detection is largely dependent on the transverse position of the wheels - the slab bends when the wheel passes along it but bends much less so when the wheel falls runs directly over the beam. This is widely accepted in the literature (Chatterjee et al., 2006; Kalin et al., 2006) and was also encountered at the Loughbrickland site. Figure 7 shows a partly loaded (22 t) class 52 vehicle where neither the axles of the tandem nor the individual axles of the tractor are distinguishable. In order to overcome this issue, new methods of axle detection were investigated.

\subsection{New strategy for axle detection}

The measurement of vertical strain on the supporting beams was assessed as an alternative axle detection strategy to instrumenting the slab, as shown in Figure 8. An initial trial was carried out to test the new approach. Unfortunately, the system

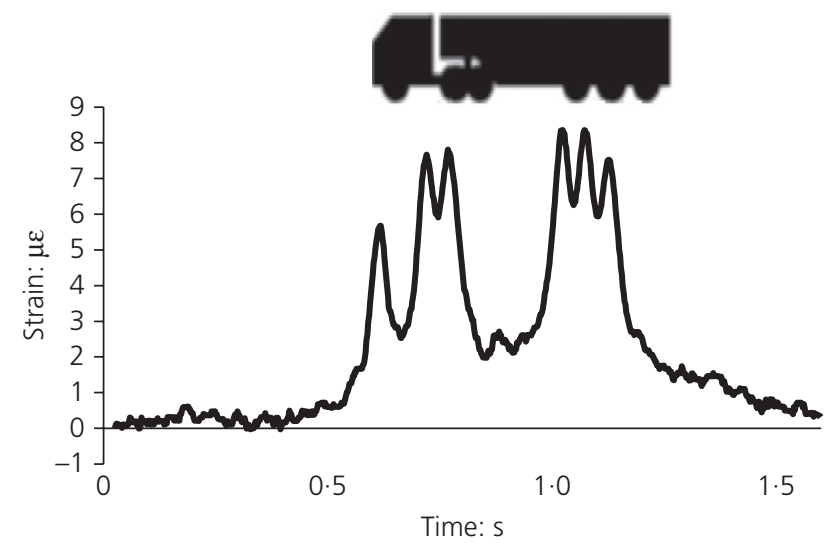

(a)

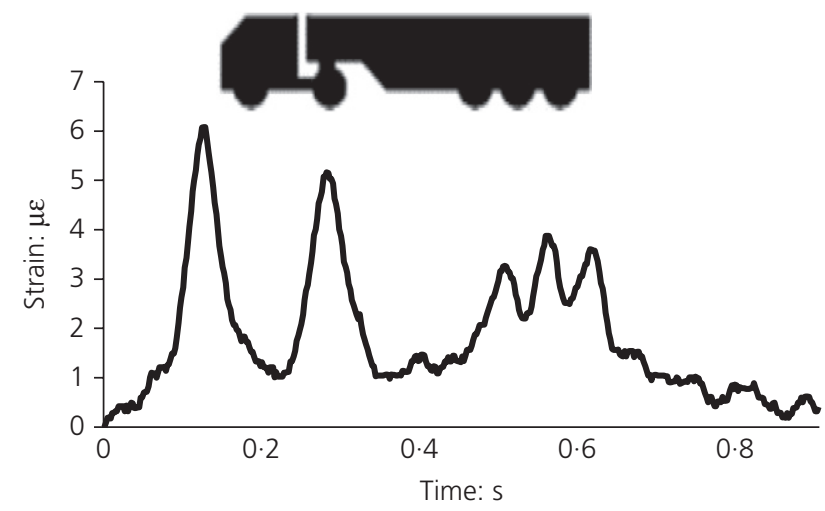

(b)

Figure 6. Clear peak detection for (a) partially loaded class 56 vehicle and (b) fully loaded class 55 vehicle

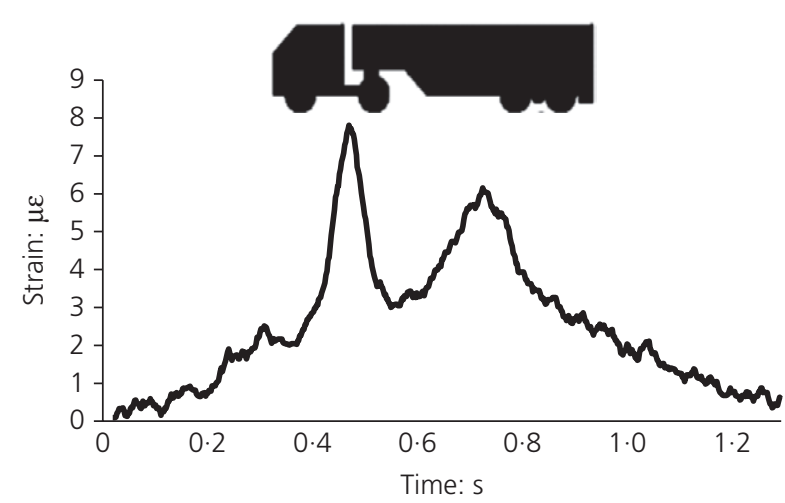

Figure 7. Class 52 vehicle with axle detection problems

was not time-synchronised with the PWIM system for this trial and therefore accurate weights for the presented vehicles are not known. 


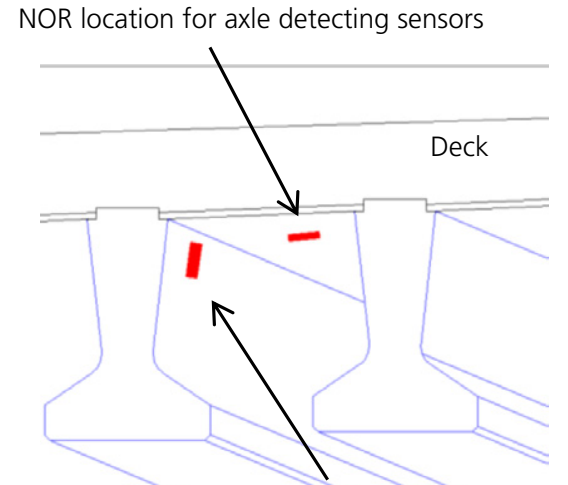

New location for axle detecting sensors

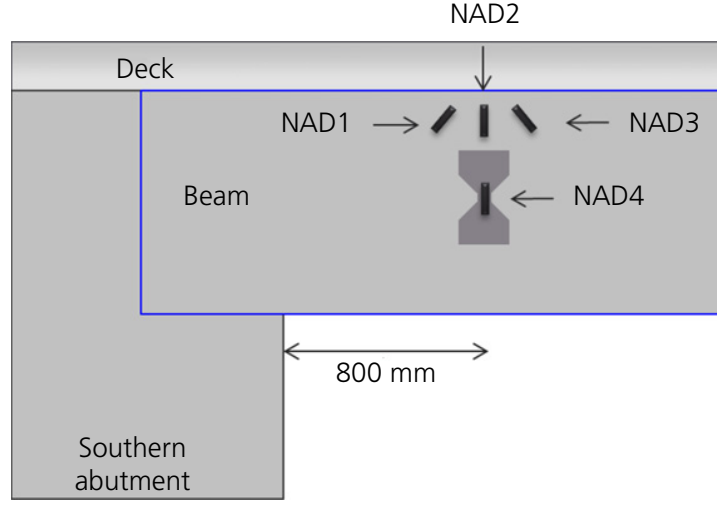

Figure 8. Location of new axle detecting sensors (NADs) and sensor numbering

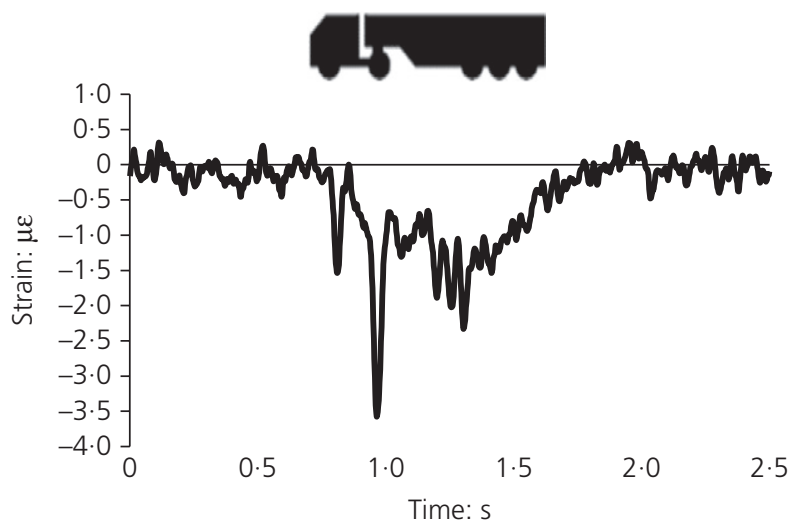

(a)

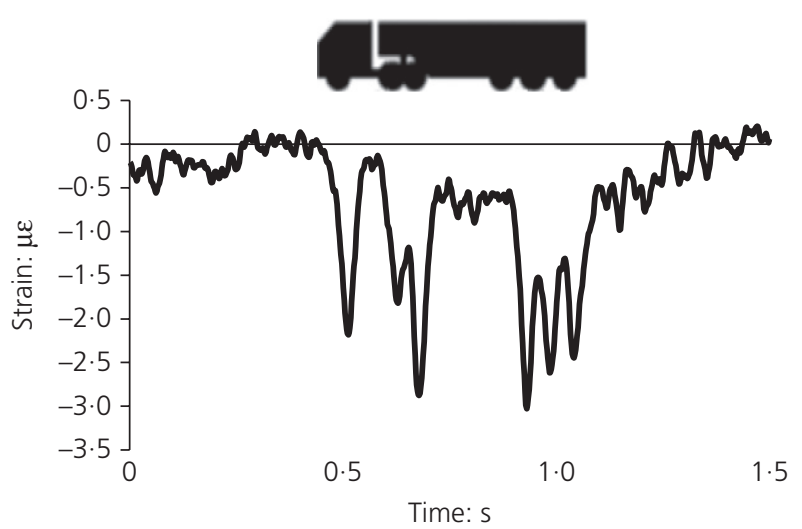

(b)

Figure 9. Peak detection of lightly loaded vehicles using new strategy for axle detection: (a) class 55 vehicle; (b) class 56 vehicle

To test the strategy rigorously, clear axle detection must be obtained for an unloaded vehicle. The second axle of the class 55 vehicle presented in Figure 9(a) is significantly heavier than

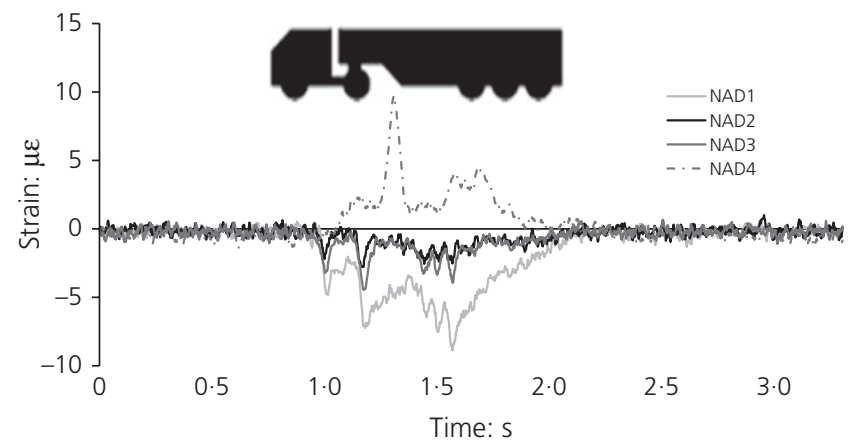

Figure 10. Response of NAD sensors to the passage of a class 55 vehicle

the rear tridem. This indicates that the truck was likely to be empty or carrying a light load. Even with a light load the individual peaks can be clearly distinguished for the tridem at the rear. This demonstrates that bearing strain measured in the beam can be used as an accurate method of axle detection. Similar results were found for the tridem of the class 56 vehicle, as shown in Figure 9(b).

The success of this trial instigated the final installation phase. This involved fixing additional sensors to the side face of beam 7. The sensor labels and orientation can be seen in Figure 8. To amplify the strain and increase the sensitivity, a new axle detecting sensor (NAD4) was fixed in place using the dog-bone plate. NAD1 and NAD3 were positioned at $45^{\circ}$ to the vertical in order to measure shear strain, which tends to change suddenly as a point load (such as an axle) passes over. The responses of all four sensors to the passing of a class 55 vehicle are shown in Figure 10. The strains measured at NAD4 are tensile, confirming that the sensor was located below the neutral axis. As with 


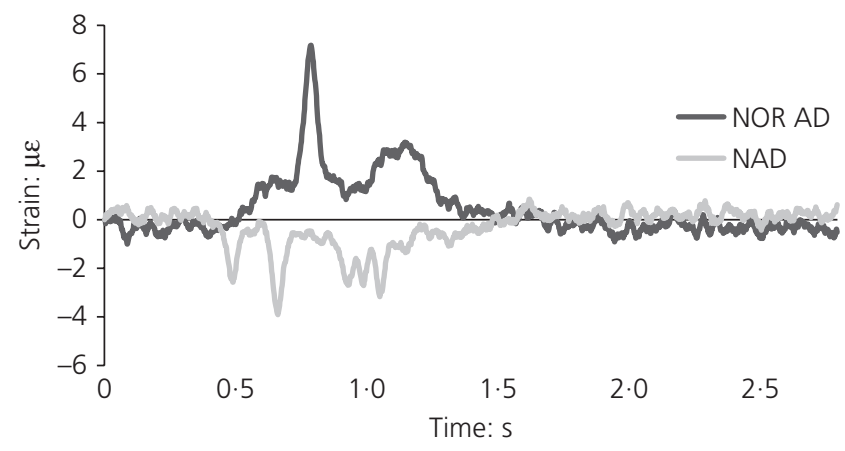

(a)

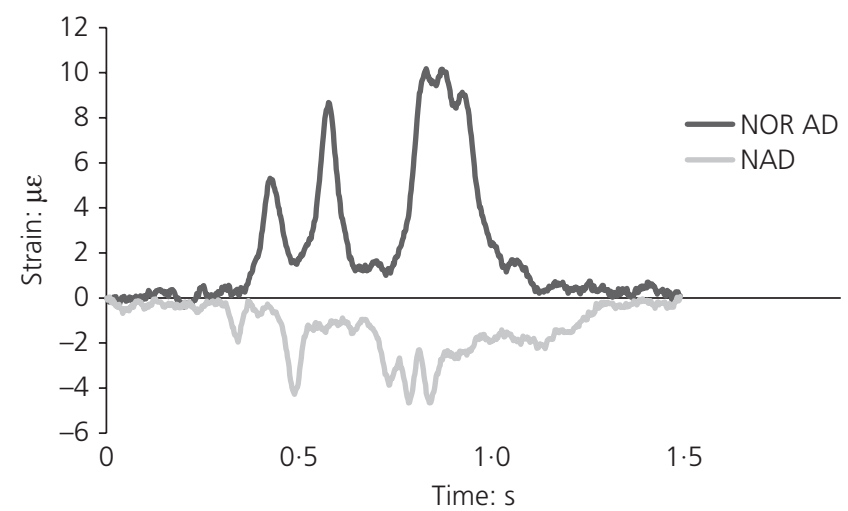

(b)

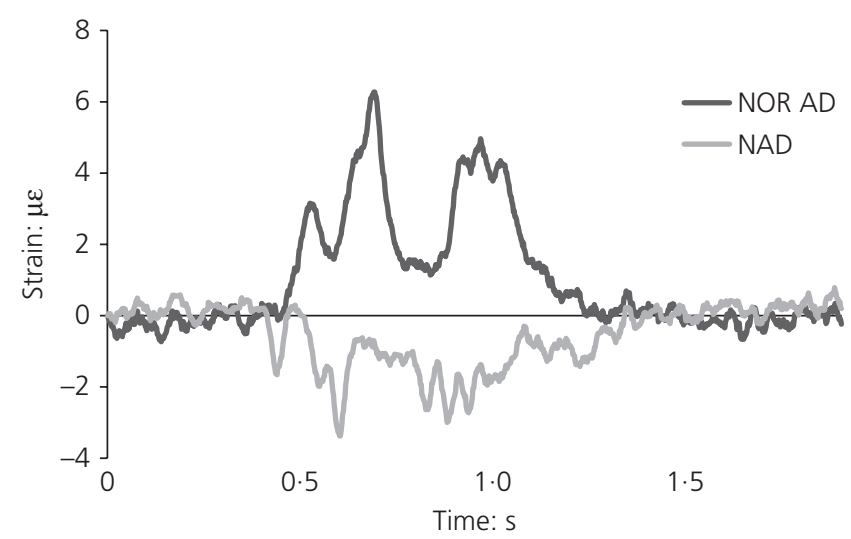

(c)

Figure 11. Comparison of responses of NAD3 and conventional sensor

all of the strain signals presented in this paper, a moving average was applied to the results.

Sensor NAD3 is seen to respond well and could provide an alternative method of axle detection. The results presented in Figure 11 compare the response of this sensor with the results obtained from sensors in the slab. In each case it is shown that NAD3 outperforms the sensor in the slab.

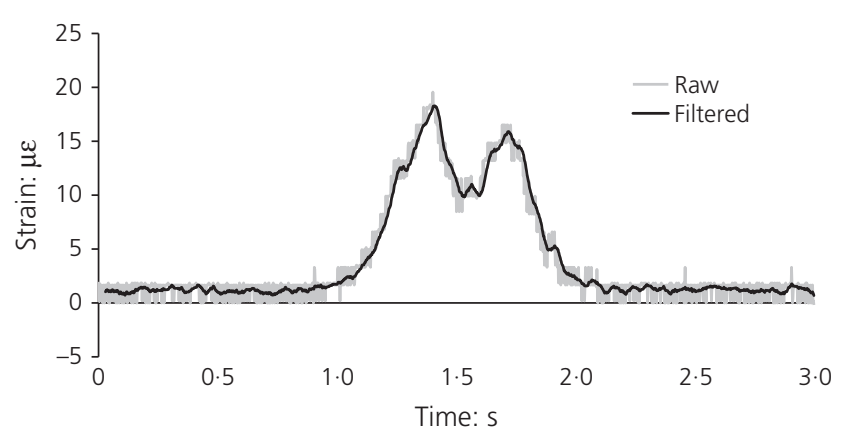

Figure 12. Strain signal induced at beam mid-span by six-axle truck

\subsection{BWIM system calibration filtered raw}

Post-processing of the BWIM strain signals obtained on site was carried out using commercially available BWIM software. This software is used to infer axle weights from the sensor signals and a detailed description of the algorithms used in the software is presented elsewhere literature (Žnidarič et al., 2010, 2011). The system is calibrated by specifying the influence line for the signal. An initial triangular influence line was updated until theoretical and measured strains matched as closely as possible (OBrien et al., 2006). The normalised influence line was found using a scaling factor found using a truck of known weight. Figure 12 shows a typical strain response at one midspan sensor location due to a moving six-axle truck on the road overhead. The raw signal and the signal after the moving average has been applied can be seen in the figure.

The post-processing was carried out at the Slovenian National Building and Civil Engineering Institute in Ljubljana and the data collected from the DVA test day of 4 October 2013 were used for calibration. The calibration truck chosen was a sixaxle articulated truck of $30 \cdot 25 \mathrm{t} \mathrm{GVW}$ as determined at a certified static scale. As the calibration truck was selected from live traffic, only one calibration run was completed. In order to determine the accuracy classification, subsequent vehicles were selected from live traffic on 4 October and 6 November 2013 (DVA test days 1 and 2 respectively) and weighed statically by the DVA.

\subsection{Accuracy classification of BWIM system}

The Cost 323 (Cost 323, 1999) specification defines seven accuracy classes: $\mathrm{A}(5), \mathrm{B}+(7), \mathrm{B}(10), \mathrm{C}(15), \mathrm{D}+(20), \mathrm{D}(25)$ and E. Accuracy class is determined by the width of the confidence interval within which a specified percentage of errors fall. While $95 \%$ is the default, some variation is allowed, depending on test conditions. Hence, for example, a system where $95 \%$ (depending on test conditions) of GVWs are within $\pm 10 \%$ is 
Table 3. Accuracy classification of FOS BWIM system

\begin{tabular}{|c|c|c|c|c|c|c|c|c|}
\hline Criterion & Number & Identified: \% & Mean error: \% & Standard deviation: \% & $\delta: \%$ & $\pi_{\mathrm{o}}: \%$ & $\pi: \%$ & Class \\
\hline GVW & 6 & $100 \cdot 0$ & $-4 \cdot 50$ & 2.45 & 10 & $60 \cdot 8$ & $85 \cdot 5$ & $B(10)$ \\
\hline Groups of axles & 8 & $100 \cdot 0$ & $-6 \cdot 14$ & $5 \cdot 79$ & 18 & 71.5 & $86 \cdot 1$ & $C(15)$ \\
\hline Single axle & 28 & $97 \cdot 0$ & $-2 \cdot 25$ & $9 \cdot 33$ & 20 & $87 \cdot 1$ & $90 \cdot 1$ & $C(15)$ \\
\hline Axles of a group & 20 & $95 \cdot 0$ & $-2 \cdot 11$ & $9 \cdot 81$ & 20 & $84 \cdot 9$ & $85 \cdot 9$ & $B(10)$ \\
\hline
\end{tabular}

$\delta$, interval width required to satisfy this class; $\pi_{0}$, minimum required level of confidence; $\pi$, actual level of confidence

class $\mathrm{B}(10)$. For a given accuracy class, wider confidence intervals are allowed for axles and axle groups than for GVW.

The test of the Loughbrickland BWIM system was carried out under 'full reproducibility conditions (R2)'; that is, a large sample of traffic representative of the traffic flow. Condition $\mathrm{R} 2$ from the Cost 323 specification is the closest representation of the true conditions of the site test; however, this condition states that tens to a hundred vehicles should cross the site to give an accurate estimation for a variety of loading conditions. Since the calibration for this system was limited to only one vehicle this condition is considered conservative. Future testing of the system would require a more rigorous calibration to measure the effect of varying vehicle speed and configuration and vehicles in other lanes, hence improving the accuracy of the system.

The dataset for the accuracy classification consists of vehicles that were statically weighed during the two separate DVA days. Therefore, the test was deemed to be under limited environmental reproducibility conditions (II) from Cost 323. The accuracy class determined from the site results is presented in Table 3. The mean error of the calculated weight for the static measured weight is given in fourth column and the standard deviation of this is shown in the fifth column. The confidence interval widths, $\delta$, for each criterion for the target levels of accuracy are given in the sixth column. The required levels of confidence (probability), $\pi_{\mathrm{o}}$, for these test conditions are given in the seventh column and the actual levels of confidence, $\pi$, can be seen to exceed these values in each case.

The overall accuracy of the system is $\mathrm{C}(15)$, groups of axles and single axles being the governing criteria. Class $\mathrm{B}(10)$ accuracy was achieved for GVW and axles of a group. Recent sensitivity studies on the accuracy of BWIM systems have found that a minimum increase of one accuracy class can be achieved by applying individual calibration factors to different types of vehicles (Corbaly et al., 2014). Future testing of this system will involve more rigorous calibration of the system to allow for this.

The mean errors for all groups were negative, which means that the system is under-weighing. However, it is acknowledged a small sample was used, particularly for GVWs and groups of axles.

\section{Conclusions}

A fibre optic bridge weigh-in-motion (BWIM) system was developed and tested on an integral bridge with a single span of $19 \mathrm{~m}$. The strain output at various locations on the bridge soffit was used to measure the response of the structure under live loading. The results presented in this paper confirm the viability of a new strategy for nothing on the road (NOR) axle detection and are consistent with the claim by Kalin et al. (2006) that fibre optic sensors would work well for BWIM. The new strategy works well for axle detection when the load passes over the beam, but performs less well when the load passes over the slab. The ideal system would therefore consist of a combination of new axle detecting sensors and NOR axle detecting sensors. A six-axle vehicle was used for calibration of the BWIM system. The gross vehicle weights and axle weights for a selection of vehicles crossing the bridge were then calculated based on this calibration. The accuracy of the system is greatly influenced by the method by which it was calibrated. Ideally, a wider range of vehicles would have been used for the calibration. More detailed studies are required to determine the true capabilities of this BWIM system, and these would involve a more accurate estimation of the influence line and rigorous testing to measure the effect of multiple presence situations and road surface roughness.

\section{Acknowledgements}

The authors acknowledge the financial support of DEL, Invest Northern Ireland, Science Foundation Ireland and the United States National Science Foundation for this research. The assistance of the Technical Staff at Queen's University Belfast and the staff at Cestel (SiWIM) and the Slovenian National Building and Civil Engineering Institute is sincerely appreciated. The authors would also like to thank the Northern Ireland Roads Service, Transport NI and the DVA for their cooperation throughout the research.

\section{REFERENCES}

Altman D and Bland J (1983) Measurement in medicine: the analysis of method comparison studies. The Statistician 32(3): 307-317.

Casas J and Cruz P (2003) Fiber optic sensors for bridge monitoring. Journal of Bridge Engineering 8(6): 362-373.

Chatterjee P, OBrien E, Li Y and González A (2006) Wavelet domain analysis for identification of vehicle axles from bridge measurements. Computers \& Structures 84(28): 1792-1801. 
Corbaly R, Žnidarič A, Leahy C et al. (2014) Algorithms for Improved Accuracy Static Bridge-WIM System. ROD, Dublin, Bridgemon D1.3 Report.

Cost 323 (2002) Weigh-in-Motion of Road Vehicles (Jacob B, O'Brien EJ and Jehaes S (eds)). LCPC, Paris, Final Report of the COST 323 Action.

Doherty C, Heanen A, Taylor S, Cleland D and Lydon M (2014) Statistical analysis of HGV bridge loading for a DBFO scheme using Northern Ireland (NI) Weigh-In-Motion (WIM) data. In Paper presented at Civil Engineering Research in Ireland Conference (CERAI), Belfast, United Kingdom.

DVSA (Driver and Vehicle Standards Agency) (2013) https://www.gov.uk/ government/uploads/system/uploads/attachment_data/file/363044/ vosa-effectiveness-report-2013-2014.xls.

González A, Rowley C and OBrien EJ (2008) A general solution to the identification of moving vehicle forces on a bridge. International Journal for Numerical Methods in Engineering 75(3): 335-354.

Hayes J and Simmonds T (2002) Interpreting strain measurements from load tests in bored piles. Proceedings of the 9th International Conference on Piling and Deep Foundations. DFI, Nice, France, pp. 3-5.

Inaudi D (2010) Overview of 40 bridge structural health monitoring projects. International Bridge Conference (IBC 2010), Pittsburgh, $P A, U S A$ (Inaudi D (ed.)).

IRC (Infrastructure Report Card) (2016) 2013 Report Card for America's Infrastructure. See http://www.infrastructurereportcard.org (accessed 14/12/2016).

Jacob B (2000) Assessment of the accuracy and classification of weighin-motion systems. Part 1: Statistical background. International Journal of Vehicle Design - Heavy Vehicle Systems 7(2-3): 136-152.

Jacob B, O'Brien E and Newton W (2000) Assessment of the accuracy and classification of weigh-in-motion systems. Part 2: European specification. International Journal of Vehicle Design - Heavy Vehicle Systems 7(2-3): 153-168.

Kalin J, Žnidarič A and Lavrič I (2006) Practical implementation of nothing-on-the- road bridge weigh-in-motion system. Proceedings of International Symposium on Heavy Vehicle Weights and Dimensions, State College, Pennsylvania, USA.

Koniditsiotis C (2000) Weigh-In-Motion Technology. Austroads Incorporated, Sydney, Australia.

Lavric I, Žnidarič A and Kalin J (2008) Improving bridge-WIM results with better road evenness and advanced compensations. In Proceedings of 5th International Conference on Weigh-in-Motion (ICWIM5) (Jacob B, O'Brien E, O'Connor A and Bouteldja M (eds)). LCPC Publications, Paris, France, pp. 271-282.

Law SS and Fang Y (2001) Moving force identification: optimal state estimation approach. Journal of Sound and Vibration 239(2): 233-254.

Law SS, Chan THT and Zeng QH (1999) Moving force identification: a frequency and time domain analysis. ASME Journal of Dynamic systems, Measurement and Control 12(3): 394-401.

Lydon M, Taylor S and Robinson D (2014) Development of a bridge weigh-in-motion sensor: performance comparison using fibre optic and electric resistance strain sensor systems. IEEE Sensors Journal 14(12): $4284-4296$

Lydon M, Taylor S, Mufti A and OBrien E (2015) Recent developments in bridge weigh in motion. Journal of Civil Structural Health Monitoring 6(1): 69-81.

Maaskant R, Alavie T, Measures RM et al. (1997) Fiber-optic Bragg grating sensors for bridge monitoring. Cement \& Concrete Composites 19(1): 21-33.

Measures RM (2001) Structural Monitoring with Fiber Optic Technology. Academic Press, San Diego, CA, USA.
Moses F (1979) Weigh-in-motion system using instrumented bridges. Transportation Engineering Journal 105(3): 233-249.

Norman OK and Hopkins RC (1952) Weighing vehicles in motion. Public Road 27(1): 1-17.

O'Brien E, Znidaric A and Dempsey A (1999) Comparison of two independently developed bridge weigh-in-motion systems. International Journal of Heavy Vehicle Systems 6(1): 147-161.

OBrien E, Quilligan M and Karoumi R (2006) Calculating an influence line from direct measurements. Proceedings of the Institution of Civil Engineers - Bridge Engineering 159(1): 31-34, http://dx.doi. org/10.1680/bren.2006.159.1.31.

OBrien E, Rowley CW, González A and Green M (2009) A regularised solution to the bridge weigh in motion equations. International Journal of Heavy Vehicle Systems 16(3): 310-327.

O'Brien E, Hajializadeh D, Uddin N, Robinson D and Opitz R (2012) Strategies for axle detection in bridge weigh-in-motion systems. Proceedings of International Conference on Weigh-In-Motion (ICWIM 6). Dallas, USA, pp. 79-88.

Peters RJ (1986) CULWAY, an unmanned and undetectable highway speed vehicle weighing system. Proceedings of 13 th $A A R B$ Conference, p. 13,6.

Richardson J, Jones S, Brown A, O'Brien E and Hajializadeh D (2014) On the use of bridge weigh-in-motion for overweight truck enforcement. International Journal of Heavy Vehicle Systems 21(2): 83-104.

Rowley CW, OBrien EJ, Gonzalez A and Žnidarič A (2009) Experimental testing of a moving force identification bridge weigh-in-motion algorithm. Experimental Mechanics 49(5): 743-746.

Zhu XQ, Law SS and Kong H (2013) Recent advances on moving force identification in structural dynamics. Proceedings of 6 th International Conference on Structural Health Monitoring of Intelligent Infrastructure, Hong Kong.

Žnidarič A and Lavrič I (2010) Applications of B-WIM technology to bridge assessment. Proceedings of 5th International Conference on Bridge Maintenance, Safety and Management, IABMAS2010, Philadelphia, PA, USA, pp. 217-220.

Žnidarič A, Lavrič I and Kalin J (2010) Latest practical developments in the Bridge WIM technology. In Proceedings of the Fifth International Conference on Bridge Maintenance, Safety and Management IABMAS2010, Philadelphia, PA, USA, pp. $993-1000$

Žnidarič A, Lavrič I, Kalin J and Kulauzović B (2011) SiWIM Bridge Weigh-in-Motion Manual, 4th edn. Cestal, ZAG, Ljubljana, Slovenia

\section{How can you contribute?}

To discuss this paper, please email up to 500 words to the editor at journals@ice.org.uk. Your contribution will be forwarded to the author(s) for a reply and, if considered appropriate by the editorial board, it will be published as discussion in a future issue of the journal.

Proceedings journals rely entirely on contributions from the civil engineering profession (and allied disciplines). Information about how to submit your paper online is available at www.icevirtuallibrary.com/page/authors, where you will also find detailed author guidelines. 